\title{
Facile, Noncovalent Decoration of Graphene Oxide Sheets with Nanocrystals
}

\author{
Ganhua Lu', Shun Mao', Sungjin Park², Rodney S. Ruoff ${ }^{2}$, and Junhong Chen ${ }^{1}(\varangle)$ \\ ${ }^{1}$ Department of Mechanical Engineering, University of Wisconsin-Milwaukee, 3200 N. Cramer St., Milwaukee, WI 53211, \\ USA \\ ${ }^{2}$ Department of Mechanical Engineering and the Texas Materials Institute, University of Texas at Austin, 204 E. Dean Keeton, Austin, \\ TX 78712, USA
}

Received: 20 November 2008/Revised: 23 December 2008/Accepted: 23 December 2008

(C) Tsinghua University Press and Springer-Verlag 2009. This article is published with open access at Springerlink.com

\begin{abstract}
Facile dry decoration of graphene oxide sheets with aerosol Ag nanocrystals synthesized from an arc plasma source has been demonstrated using an electrostatic force directed assembly technique at room temperature. The Ag nanocrystal-graphene oxide hybrid structure was characterized by transmission electron microscopy (TEM) and selected area diffraction. The ripening of Ag nanocrystals on a graphene oxide sheet was studied by consecutive TEM imaging of the same region on a sample after heating in Ar at elevated temperatures of $100{ }^{\circ} \mathrm{C}, 200{ }^{\circ} \mathrm{C}$, and $300{ }^{\circ} \mathrm{C}$. The average size of $\mathrm{Ag}$ nanocrystals increased and the number density decreased after the annealing process. In particular, migration and coalescence of $\mathrm{Ag}$ nanocrystals were observed at a temperature as low as $100{ }^{\circ} \mathrm{C}$, suggesting a van der Waals interaction between the $\mathrm{Ag}$ nanocrystal and the graphene oxide sheet. The availability of affordable graphene-nanocrystal structures and their fundamental properties will open up new opportunities for nanoscience and nanotechnology and accelerate their applications.
\end{abstract}

\section{KEYWORDS}

Graphene oxide, silver nanocrystals, hybrid nanostructures, nanocrystal ripening

\section{Introduction}

Research interest in graphene, a flat monolayer of $\mathrm{sp}^{2}$-bonded carbon atoms tightly packed into a two-dimensional (2-D) honeycomb lattice [1] with thickness of $0.335 \mathrm{~nm}$ [2], has grown dramatically since experimental transport measurements were reported in 2004 on samples made by mechanical exfoliation of graphite [3]. The mechanical [4], thermal [5], optical [6], and electrical [1, 3] properties of graphene are exceptional. For example, graphene was reported to outperform carbon nanotubes (CNTs) in room temperature heat conduction [5]. Graphene has extremely high electron mobility at room temperature and a resistivity of $10^{-6} \Omega \cdot \mathrm{cm}$, which is comparable to that of silver $\left(1.62 \times 10^{-6} \Omega \cdot \mathrm{cm}\right)$, a material widely known for having the lowest resistivity at room temperature. Moreover, electron transport in graphene has been reported to be ballistic up to $0.3 \mu \mathrm{m}$ at $300 \mathrm{~K}$ [1]. The unique and outstanding

Address correspondence to jhchen@uwm.edu 
properties of graphene make it an ideal candidate in a wide range of applications, including fieldeffect transistors $[7,8]$, composite materials $[9,10]$, field emitters [11], gas sensors [12-14], hydrogen storage media [15-17], and transparent conducting electrodes [18-20].

Functionalization of graphene sheets with various chemical groups and nanocrystals can further enhance the properties of graphene. Hybrid materials consisting of nanocrystals distributed on the surface of graphene could potentially display not only the unique properties of nanocrystals [21,22] and those of graphene $[1,3,23,24]$, but also additional novel properties due to the interaction between the nanocrystals and the graphene. Many exciting applications can be envisioned for these novel hybrid structures, such as in nanocomposites, chemical sensors, biosensors, nanoelectronics, photovoltaic cells, fuel cells, and perhaps for hydrogen storage. Solution-based chemical methods have been reported for the production of graphene-metal [25] and graphene-semiconductor [26] hybrid structures; however, these methods typically involve complex processes and are time consuming. The attachment of nanocrystals to a graphene sheet in these cases was attributed to physisorption, electrostatic binding, or charge transfer interactions $[25,26]$.

We recently developed a facile and materialindependent dry route-electrostatic force directed assembly (ESFDA) - for the assembly of nanocrystals onto both randomly dispersed CNTs [27-30] and vertically aligned CNTs [28] without the need for chemical functionalization of CNTs. Here we report the assembly of aerosol nanocrystals (e.g., Ag) onto graphene oxide sheets (generated by simple sonication of graphite oxide (GO) in water) that have their basal planes and edges decorated with oxygen functional groups [31-33], using the ESFDA technique. Graphene-nanocrystal structures can then be obtained by reducing graphene oxide to graphene using reducing agents, such as hydrazine hydrate [34], $\mathrm{NaBH}_{4}$ [25], high temperature treatment [19], or through UV-assisted photocatalysis [26]. Since the assembly is realized at room temperature in an inert gas, the chance of having noncovalent binding between nanocrystal and graphene oxide sheet is enhanced, in contrast to the situation for higher temperatures or more reactive environments. In addition, the behavior of the nanocrystal-graphene structure at elevated temperatures is critical for many applications that require higher-than-ambient temperatures where ripening of nanocrystals may occur. Thus, following deposition of aerosol Ag nanocrystals onto graphene oxide sheets, the hybrid structure was annealed in an Ar flow in order to probe the interaction between the nanocrystals and the graphene oxide sheet and the influence of elevated temperatures on nanocrystal size distribution, binding, and morphology.

\section{Experimental}

GO was synthesized by the oxidative treatment of purified natural graphite (SP-1, Bay Carbon, MI) using a modified Hummers method [35]. The material was then fully exfoliated in water to produce suspensions of single sheets of graphene oxide. The presence of oxygen functional groups makes graphene oxide sheets strongly hydrophilic; stable aqueous dispersions consisting almost entirely of sheets with a thickness of $1 \mathrm{~nm}$ can be obtained by a mild ultrasonic treatment of graphite oxide in water [34].

A few drops of the graphene oxide suspension were cast onto transmission electron microscopy (TEM) grids and graphene oxide sheets were left on grids after the solvent evaporated. Two types of TEM grids were used: one made of $\mathrm{Cu}$ covered with a thin layer of holey carbon film, which is helpful for observing large area graphene oxide sheets; the other made of bare Ni grid, which is thermally stable and improves the likelihood of retaining regions of interest during the course of sample handling and annealing. The Ni grid was also indexed to help track specific sample locations on the grid.

A schematic diagram of the aerosol nanocrystal synthesis and the subsequent ESFDA process is shown in Fig. 1. The aerosol silver nanocrystals were produced through physical vaporization of a solid precursor material (Ag wire, 99.999\% purity, ESPICorp. Inc.) using a mini-arc plasma source sustained between a tungsten cathode and a graphite anode [36]. The as-produced Ag nanocrystals were 


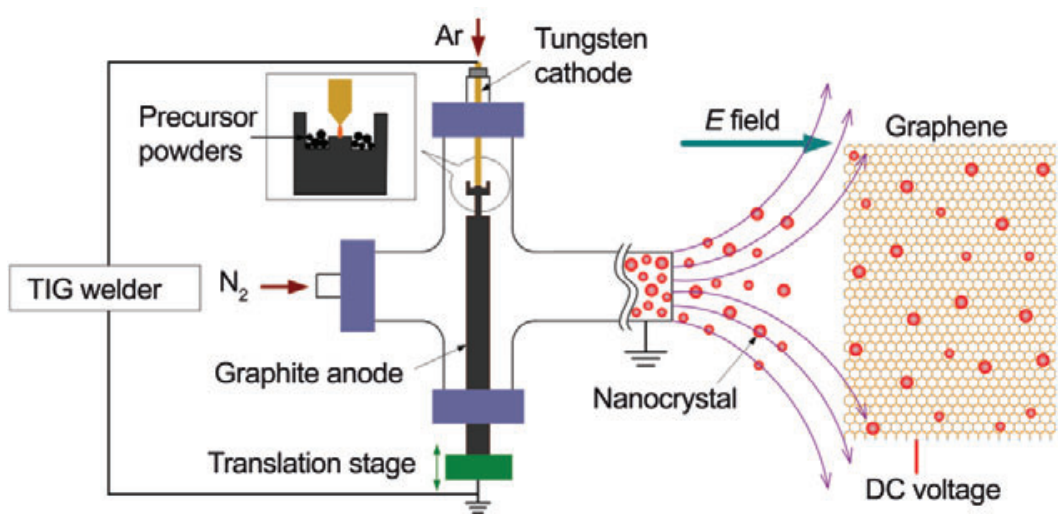

Figure 1 Schematic diagram of Ag nanocrystal synthesis using a mini-arc plasma reactor and the subsequent deposition of as-produced nanocrystals onto a graphene oxide sheet through ESFDA

nonagglomerated with a fraction of the resulting nanocrystals being charged electrically, which facilitated their directed assembly in an external electric field. The aerosol nanocrystals were carried by room temperature inert gases $\left(\mathrm{Ar} / \mathrm{N}_{2}, 5.0 / 4.5\right.$ lpm (liters per minute)) into a gap between two electrodes to form a stagnation flow. One electrode was the grounded metal tubing that introduced the aerosol nanocrystals. The other electrode, which was applied with a direct current (DC) voltage $(V)$, was the TEM grid containing graphene oxide sheets. With a DC voltage applied to the conductive grid, oppositely charged aerosol nanocrystals were assembled onto the surface of graphene oxide sheets. Typical assembly times are on the order of minutes. It is unlikely that nanocrystals on the graphene oxide surface are produced by breaking down larger source particles under these deposition conditions since our earlier experiments showed the preservation of nanoparticle size during the deposition of monodisperse $\mathrm{Au}$ nanoparticles onto CNTs under similar conditions [37].

Both graphene oxide sheets and Ag-graphene oxide hybrid structures were analyzed using a Hitachi H 9000 NAR TEM, which has a point resolution of $0.18 \mathrm{~nm}$ at $300 \mathrm{kV}$ in the phase contrast high-resolution TEM (HRTEM) imaging mode. The TEM analyses included amplitude-contrast bright field (BF) images, HRTEM images, and selected area diffraction (SAD) patterns.

Several regions of Ag nanocrystal-decorated graphene oxide sheets on the Ni TEM grid were identified and imaged prior to conducting the heating experiments. After the target regions were selected, the sample was heated in a tube furnace (Lindberg Blue, TF55035A-1) for one hour at each elevated temperature $\left(100{ }^{\circ} \mathrm{C}, 200{ }^{\circ} \mathrm{C}\right.$, and $\left.300{ }^{\circ} \mathrm{C}\right)$ while an Ar flow of $0.8 \mathrm{lpm}$ was maintained during the process. At the end of each heating cycle, the sample was quickly cooled to room temperature in Ar flow and then imaged with the TEM. Three consecutive heating cycles in the sequence $100{ }^{\circ} \mathrm{C}, 200^{\circ} \mathrm{C}$, and $300{ }^{\circ} \mathrm{C}$ were performed on the same sample.

\section{Results and discussion}

A graphene oxide sheet with lateral dimensions of about $2 \mu \mathrm{m}$ sitting on a holey carbon film is shown in Fig. 2(a). Most parts of the sheet, particularly the central area, are homogeneous and quite smooth, while the edges tend to fold and roll. The SAD of the sheet (inset of Fig. 2(a)) displays continuous ring patterns, implying the crystallinity and the multilayer nature of the sheet; the two diffraction rings correspond to graphene crystal planes $(0 \overline{1} 10)$ (interplanar spacing of $0.213 \mathrm{~nm}$ ) and (1210) (interplanar spacing of $0.123 \mathrm{~nm}$ ) [38], consistent with the results reported for multilayer graphene films [19]. Lattice fringes are visible on the edges of graphene oxide sheets due to folds and/or rolls, as can be seen in the HRTEM image in Fig. 2(b). The separation between neighboring fringes was measured as $\sim 0.5 \mathrm{~nm}$ and is larger than the interplanar spacing in graphite $(0.34 \mathrm{~nm})$ [39], which can be attributed to the presence of oxygen functional groups on the graphene oxide layers as well as the possible inclusion of interlamellar molecules.

Figure 2(c) shows a TEM image of the same graphene oxide sheet (Fig. 2(a)) coated with Ag nanocrystals, which are distributed quite uniformly on the surface of the sheet. In addition to diffraction rings from the original graphene oxide sheet (inset in Fig. 2(a)), two sets of spots corresponding to Ag (111) and (311) crystal planes were found in 


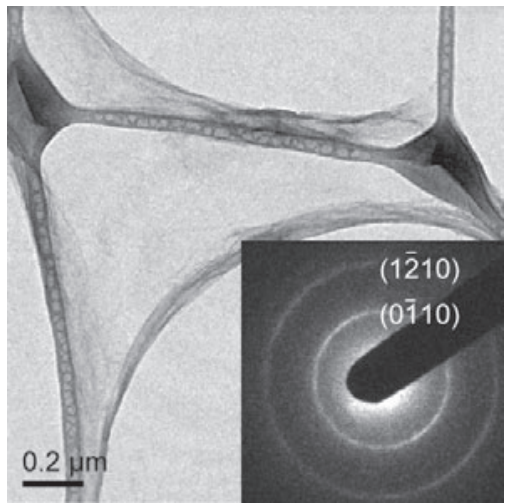

(a)

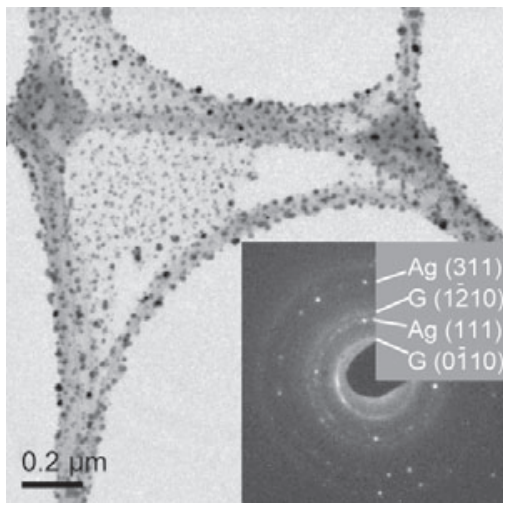

(c)

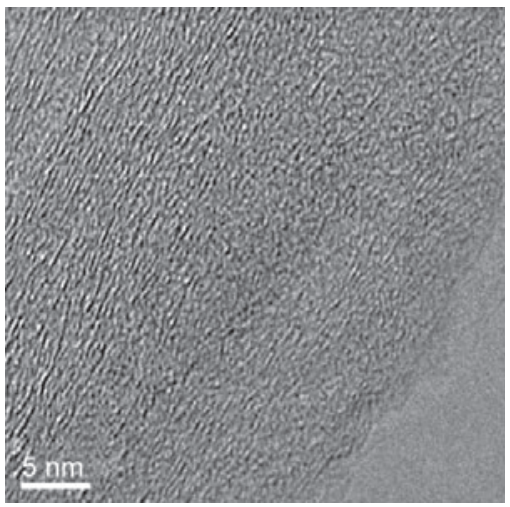

(b)

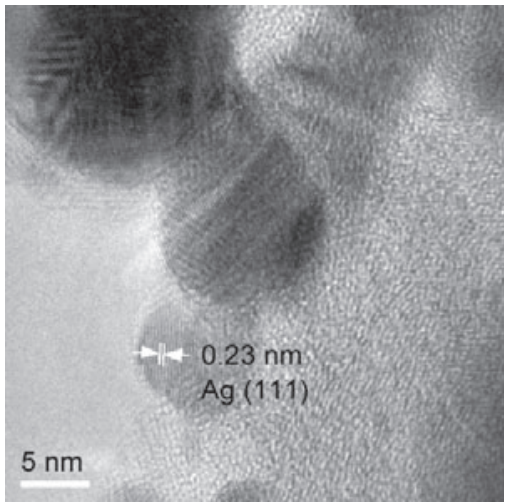

(d)
Figure 2 Low magnification TEM ((a), (c)) and HRTEM ((b), (d)) images of a multilayer graphene oxide sheet before (a) and (b), and after (c) and (d) decoration of aerosol Ag nanocrystals. The HRTEM image (b) shows the folded edge of the bare graphene oxide sheet. The lattice spacing of the Ag nanocrystals in (d) is measured as $0.23 \mathrm{~nm}$, corresponding to the $\mathrm{Ag}(111)$ crystal plane. The insets in (a) and (c) are the SAD patterns from a bare graphene oxide sheet and from an Ag-graphene oxide sheet, respectively

randomly chosen measured for each case in an effort to achieve the desired statistical significance.

During the annealing process, smaller Ag nanocrystals migrated and merged on the graphene oxide sheet to form larger Ag nanocrystals; ripening evidently occurred during the heating process at a temperature as low as $100{ }^{\circ} \mathrm{C}$. As a result of the ripening, the number density of Ag nanocrystals on the graphene sheet decreased whereas the average size $\left(D_{\mathrm{p}}\right)$ of Ag nanocrystals increased. The corresponding average size of $\mathrm{Ag}$ nanocrystals increased from $6.18 \mathrm{~nm}$ at room temperature to $8.18 \mathrm{~nm}, 8.60 \mathrm{~nm}$, and $9.03 \mathrm{~nm}$ after the $1 \mathrm{~h}$ heating process at $100{ }^{\circ} \mathrm{C}, 200{ }^{\circ} \mathrm{C}$, and $300{ }^{\circ} \mathrm{C}$, respectively.

To further determine the influence of thermal treatment on the behavior of $\mathrm{Ag}$ nanocrystals on the graphene oxide sheet, Ag nanocrystals numbered from 1 to 10 (Fig. 3(a)) were tracked over the annealing process. Smaller nanocrystals moved and joined together with more ease than larger nanocrystals, most likely due to the lower activation energy required for the migration. After the first heating cycle at $100{ }^{\circ} \mathrm{C}$ for $1 \mathrm{~h}$, nanocrystals 1 and 2 ,

the SAD pattern (inset in Fig. 2(c)) of the hybrid nanostructure. The structure of the Ag-graphene oxide hybrid structure is further demonstrated in the HRTEM image shown in Fig. 2(d), with Ag nanocrystals of about $5-10 \mathrm{~nm}$ being attached to the graphene oxide sheet. The measured lattice fringe of $0.23 \mathrm{~nm}$ corresponds to the (111) crystal plane of Ag.

Figure 3 shows a series of representative TEM images of a sample of Ag-graphene oxide hybrid structure before (Fig. 3(a)) and after being heated in Ar flow at $100{ }^{\circ} \mathrm{C}$ (Fig. 3(c)), $200{ }^{\circ} \mathrm{C}$ (Fig. 3(e)), and $300{ }^{\circ} \mathrm{C}$ (Fig. 3(g)) for $1 \mathrm{~h}$, respectively each, together with the corresponding Ag nanocrystal size distributions (Figs. 3(b), 3(d), 3(f), and 3(h)). The nanocrystal size was determined by recording the largest dimension of a nanocrystal observed in TEM images. About 300-400 Ag nanocrystals were which were the smallest two among all the marked particles, migrated and completely coalesced to form a larger and spherical nanocrystal 1'; nanocrystals 3 and 4 moved together to form nanocrystal $3^{\prime}$ but full coalescence was not obtained. A similar situation was observed for nanocrystals 9 and 10 forming $9^{\prime}$; nanocrystals 5 and 6 formed $5^{\prime}$ with slight coalescence; nanocrystals 7 and 8, the largest two of all the labeled ones, moved closer and were about to make contact with each other $\left(7^{\prime}\right.$ and $\left.8^{\prime}\right)$. With the completion of the second heating at $200{ }^{\circ} \mathrm{C}$ for $1 \mathrm{~h}$, nanocrystals $3^{\prime \prime}$ and $5^{\prime \prime}$ (Fig. 3(e)), which were the descendants of nanocrystals $3^{\prime}$ and $5^{\prime}$, respectively, coalesced further; nanocrystals $7^{\prime}$ and $8^{\prime}$ started to form $7^{\prime \prime}$. When the final heat treatment at $300{ }^{\circ} \mathrm{C}$ for $1 \mathrm{~h}$ was finished, nanocrystal $3^{\prime \prime \prime}$ was more spherical than its ancestor (particle $3^{\prime \prime}$ ), implying that

\section{基 Springer}




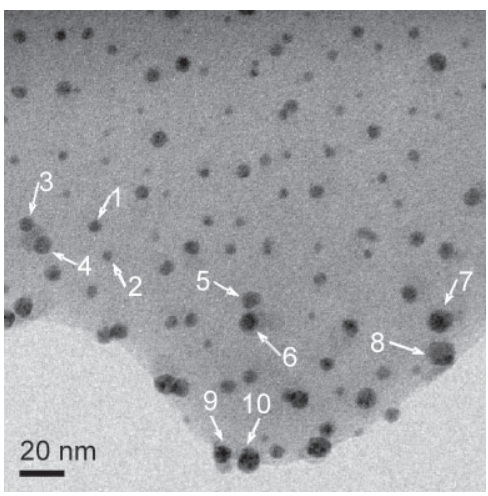

(a)

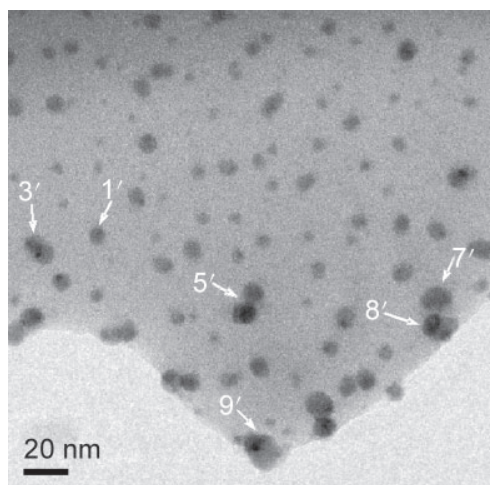

(c)

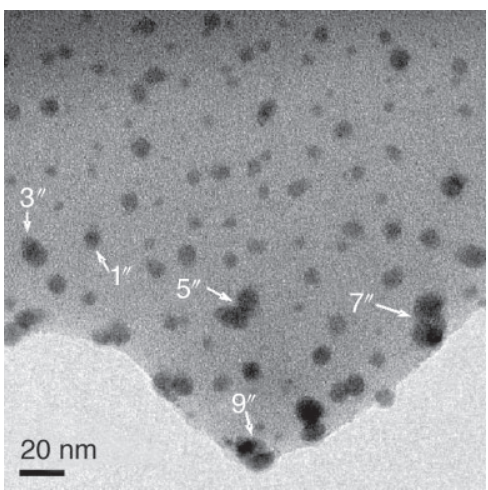

(e)

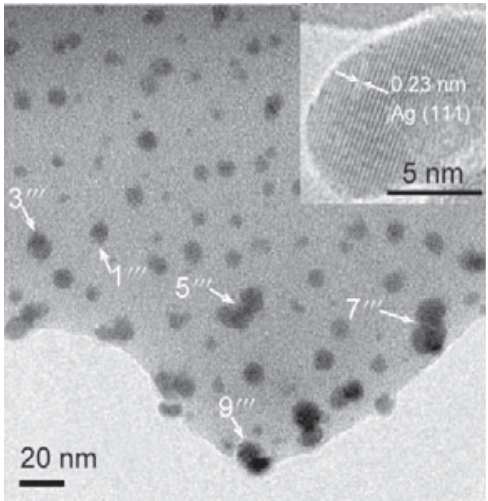

(g)

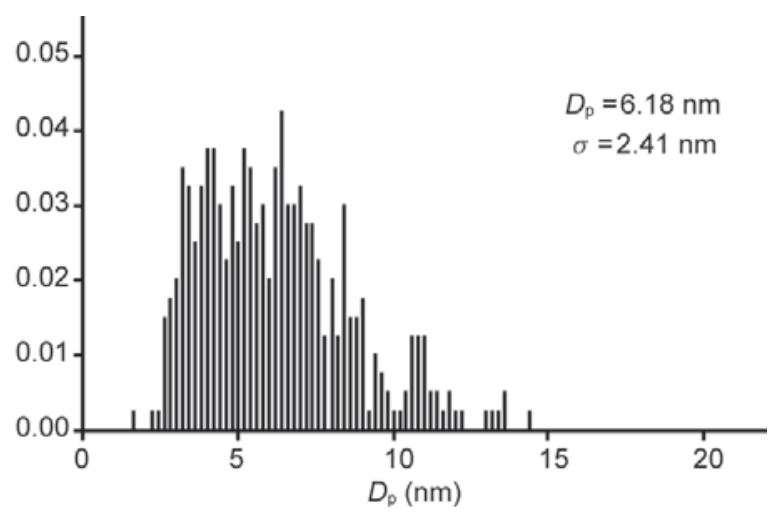

(b)

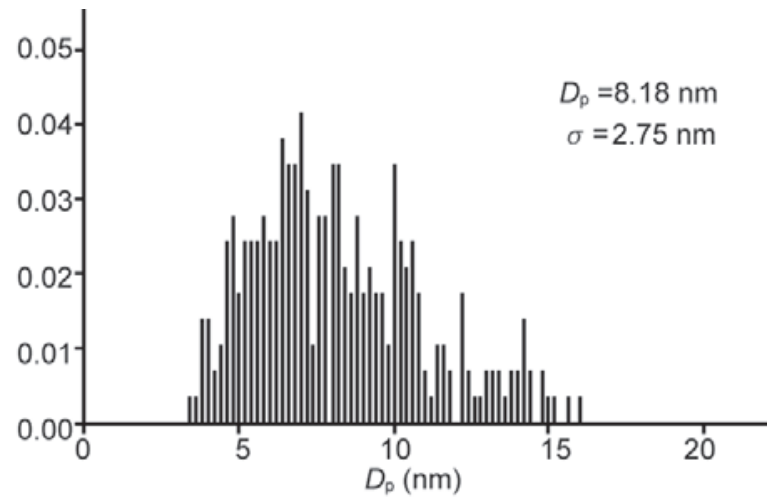

(d)

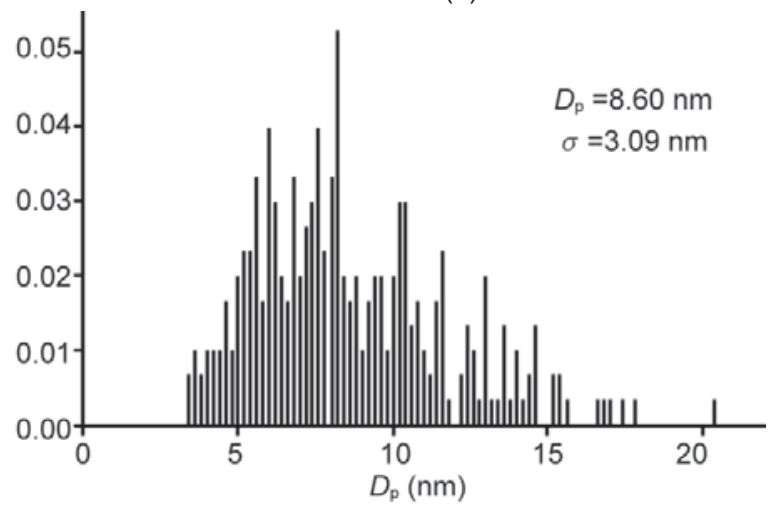

(f)

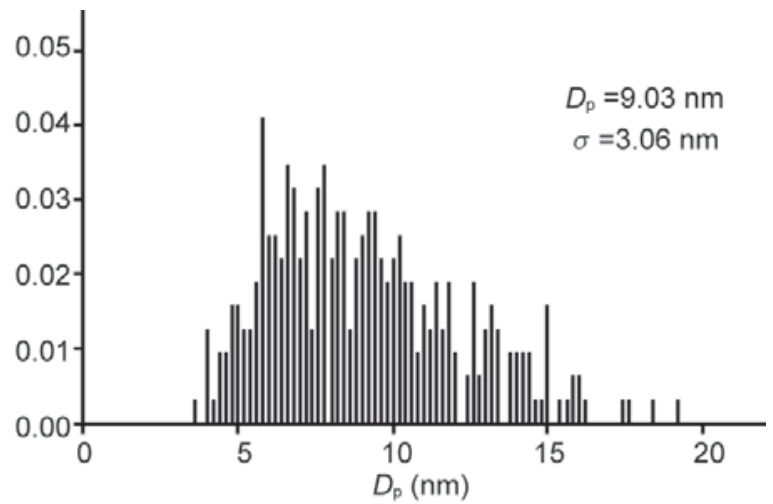

(h)

Figure 3 Left column: TEM images of a Ag-decorated graphene oxide sheet before thermal treatment (a) and after being heated for $1 \mathrm{~h}$ at $100{ }^{\circ} \mathrm{C}(\mathrm{c}), 200^{\circ} \mathrm{C}(\mathrm{e})$, and $300^{\circ} \mathrm{C}(\mathrm{g})$; Right column (b), (d), (f), and (h): corresponding Ag nanocrystal size distributions (particle number fraction versus particle diameter). The inset in $(\mathrm{g})$ is an HRTEM image of a Ag nanocrystal after experiencing the three heating cycles 
coalescence was almost complete; in contrast, larger nanocrystals $5^{\prime \prime \prime}, 7^{\prime \prime \prime}$, and $9^{\prime \prime \prime}$ were still in the process of coalescence. The crystallinity of Ag nanocrystals was found to be unchanged after the thermal treatments. A silver nanocrystal that experienced all the three heating cycles bears lattice fringes of $\mathrm{Ag}$ (111) as shown in the inset of Fig. 3(g). No oxidation was observed for the Ag nanocrystal after the thermal treatments in Ar.

The ripening of $\mathrm{Ag}$ particles/clusters has been studied on other surfaces, e.g., Ag (111) [40], alumina [41], glass and oxide-coated glass [42], and CNTs [43], or when embedded in soda glass [44] and polymer films [45]. Two possible mechanisms, Ostwald ripening and particle migration and coalescence $[46,47]$, are believed to be responsible for the ripening process. In an Ostwald ripening process, atomic species from smaller particles transport to larger particles either by surface diffusion along the substrate or by vapor phase diffusion due to the difference in the chemical potentials between smaller and larger particles. According to the particle migration and coalescence mechanism, smaller particles migrate on the substrate surface and then collide/ coalesce with larger particles.

Given the negligible vapor pressure of silver even at $300{ }^{\circ} \mathrm{C}$ [36], the chance of atomic Ag desorption (Ostwald ripening) is very low. Although it is difficult to exclude the possibility of Ostwald ripening merely based on the change in particle size distribution before and after annealing [48], comparison of successive TEM images has allowed us to observe the occurrence of $\mathrm{Ag}$ nanocrystal migration and coalescence in our experiments. The migration of Ag nanocrystals at temperatures well below the bulk melting point $\left(962{ }^{\circ} \mathrm{C}\right.$ ) suggests a low activation energy barrier for the nanocrystal movement, i.e., a weak van der Waals interaction between Ag nanocrystals and the graphene oxide sheet can be inferred. However, the interaction between the Ag nanocrystals and the graphene oxide sheet is sufficient to prevent the thermal desorption of entire Ag nanocrystals. Simple calculations show that the associated van der Waals energy between the $\mathrm{Ag}$ nanocrystal and the graphene oxide sheet is one order of magnitude larger than the thermal energy of the Ag nanocrystal even at $300^{\circ} \mathrm{C}$.
It is believed that there are epoxide and hydroxyl groups on the basal plane (on each side, top and bottom), and carbonyl and carboxyl groups on the edges of graphene oxide [31]. Thus, it is possible for Ag nanocrystals to bind to the "graphene-like" carbon in regions where there are unsaturated carbon atoms (i.e., clusters of graphene-like atoms) or to oxygen functional groups on graphene oxide. The possible interaction between Ag nanocrystals and the various regions on graphene oxide needs further investigation as it is well known that Ag atoms, particularly $\mathrm{Ag}^{+}$, can have strong interactions with the $\pi$ orbitals of alkenes [49], as one example of a more direct chemical interaction in addition to the van der Waals interaction. The noncovalent nature of the adhesion between nanocrystals and graphenelike carbon may preserve the $\mathrm{sp}^{2}$ hybridization of carbon atoms and the unique intrinsic properties of the graphene sheets.

It is likely that the graphene oxide sheets were partially reduced during the annealing process in this study. Although the annealing temperature is relatively low $\left(300{ }^{\circ} \mathrm{C}\right.$ at maximum), the heating time ( $1 \mathrm{~h}$ each at $100{ }^{\circ} \mathrm{C}, 200{ }^{\circ} \mathrm{C}$, and $300^{\circ} \mathrm{C}$ ) is relatively long. Both temperature and duration affect the extent of reduction of graphite oxide powder as well as of exfoliated graphene oxide sheets. Yang et al. [50] reported partial reduction of graphene oxide by exposure to an Ar flow at $200{ }^{\circ} \mathrm{C}$ for 30 min and reported that the carbon-to-oxygen atomic ratio increased from $2.8 \pm 0.1$ to $3.9 \pm 0.1$. graphene oxide is electrically insulating; however, it was reported that the electrical conductivity of individual graphene oxide sheets increased significantly after heating in vacuum at only $125-240{ }^{\circ} \mathrm{C}$, indicating a partial reduction of the graphene oxide [51]. Thermal treatments at $1100{ }^{\circ} \mathrm{C}$ in vacuum [52] or $\mathrm{Ar} / \mathrm{H}_{2}$ flow [19], or at $400{ }^{\circ} \mathrm{C}$ with hydrazine vapor treatment beforehand, also yield a significantly reduced material [52]. Further investigation is under way to identify the chemical status of the graphene oxide sheets under the various annealing conditions employed here.

\section{Conclusions}

Aerosol Ag nanocrystals synthesized using an 
arc plasma reactor were successfully deposited onto graphene oxide sheets at room temperature using ESFDA. The ESFDA technique is materialindependent and thus useful for the assembly of various nanocrystals onto graphene/graphene oxide sheets with a high efficiency. The interaction between the Ag nanocrystal and the graphene oxide sheet was studied by annealing the hybrid structure in $\mathrm{Ar}$ for $1 \mathrm{~h}$ at $100{ }^{\circ} \mathrm{C}, 200{ }^{\circ} \mathrm{C}$, and $300{ }^{\circ} \mathrm{C}$, respectively. Observation of migration and coalescence of $\mathrm{Ag}$ nanocrystals on the graphene oxide sheet after annealing at a relatively low temperature suggests that the Ag nanocrystal is bound to the sheet through van der Waals forces rather than by covalent bonds. The study sheds light on the fundamental properties of hybrid graphene-nanocrystal structures that are pertinent to their potential applications, especially those requiring elevated temperatures. The noncovalent nature of the nanocrystal attachment is potentially beneficial for electronic and optoelectronic applications of the reported hybrid nanostructures.

\section{Acknowledgements}

This work was financially supported by the National Science Foundation through grant CMMI-0609059. TEM analyses were performed in the HRTEM Laboratory at University of Wisconsin-Milwaukee. The authors thank D. A. Dikin for providing samples of graphene oxide, M. Gajdardziska-Josifovska for providing TEM access, and D. Robertson for technical support with TEM analyses.

\section{References}

[1] Geim, A. K.; Novoselov, K. S. The rise of graphene. Nat. Mater. 2007, 6, 183-191.

[2] Ni, Z. H.; Wang, H. M.; Kasim, J.; Fan, H. M.; Yu, T.; Wu, Y. H.; Feng, Y. P.; Shen, Z. X. Graphene thickness determination using reflection and contrast spectroscopy. Nano Lett. 2007, 7, 2758-2763.

[3] Novoselov, K. S.; Geim, A. K.; Morozov, S. V.; Jiang, D.; Zhang, Y.; Dubonos, S. V.; Grigorieva, I. V.; Firsov, A. A. Electric field effect in atomically thin carbon films. Science 2004, 306, 666-669.
[4] Frank, I. W.; Tanenbaum, D. M.; Van der Zande, A. M.; McEuen, P. L. Mechanical properties of suspended graphene sheets. J. Vac. Sci. Technol. B 2007, 25, 25582561.

[5] Balandin, A. A.; Ghosh, S.; Bao, W. Z.; Calizo, I.; Teweldebrhan, D.; Miao, F.; Lau, C. N. Superior thermal conductivity of single-layer graphene. Nano Lett. 2008, 8, 902-907.

[6] Nair, R. R.; Blake, P.; Grigorenko, A. N.; Novoselov, K. S.; Booth, T. J.; Stauber, T.; Peres, N. M. R.; Geim, A. K. Fine structure constant defines visual transparency of graphene. Science 2008, 320, 1308.

[7] Li, X. L.; Wang, X. R.; Zhang, L.; Lee, S. W.; Dai, H. J. Chemically derived, ultrasmooth graphene nanoribbon semiconductors. Science 2008, 319, 1229-1232.

[8] Semenov, Y. G.; Kim, K. W.; Zavada, J. M. Spin field effect transistor with a graphene channel. Appl. Phys. Lett. 2007, 91, 153105.

[9] Stankovich, S.; Dikin, D. A.; Dommett, G. H. B.; Kohlhaas, K. M.; Zimney, E. J.; Stach, E. A.; Piner, R. D.; Nguyen, S. T.; Ruoff, R. S. Graphene-based composite materials. Nature 2006, 442, 282-286.

[10] Ramanathan, T.; Abdala, A. A.; Stankovich, S.; Dikin, D. A.; Herrera-Alonso, M.; Piner, R. D.; Adamson, D. H.; Schniepp, H. C.; Chen, X.; Ruoff, R. S.; Nguyen, S. T.; Aksay, I. A.; Prud'homme, R. K.; Brinson, L. C. Functionalized graphene sheets for polymer nanocomposites. Nat. Nanotechnol. 2008, 3, 327-331.

[11] Wang, S. G.; Wang, J. J.; Miraldo, P.; Zhu, M. Y.; Outlaw, R.; Hou, K.; Zhao, X.; Holloway, B. C.; Manos, D.; Tyler, T.; Shenderova, O.; Ray, M.; Dalton, J.; McGuire, G. High field emission reproducibility and stability of carbon nanosheets and nanosheet-based backgated triode emission devices. Appl. Phys. Lett. 2006, 89, 183103

[12] Schedin, F.; Geim, A. K.; Morozov, S. V.; Hill, E. W.; Blake, P.; Katsnelson, M. I.; Novoselov, K. S. Detection of individual gas molecules adsorbed on graphene. Nat. Mater. 2007, 6, 652-655.

[13] Qazi, M.; Vogt, T.; Koley, G. Trace gas detection using nanostructured graphite layers. Appl. Phys. Lett. 2007, $91,233101$.

[14] Qazi, M.; Vogt, T.; Koley, G. Two-dimensional signatures for molecular identification. Appl. Phys. Lett. 2008, 92, 103120.

[15] Patchkovskii, S.; Tse, J. S.; Yurchenko, S. N.; Zhechkov, L.; 
Heine, T.; Seifert, G. Graphene nanostructures as tunable storage media for molecular hydrogen. P. Natl. Acad. Sci. USA 2005, 102, 10439-10444.

[16] Park, N.; Hong, S.; Kim, G.; Jhi, S. H. Computational study of hydrogen storage characteristics of covalentbonded graphenes. J. Am. Chem. Soc. 2007, 129, 8999 -9003 .

[17] Boukhvalov, D. W.; Katsnelson, M. I.; Lichtenstein, A. I. Hydrogen on graphene: Electronic structure, total energy, structural distortions and magnetism from first-principles calculations. Phys. Rev. B 2008, 77, 035427.

[18] Watcharotone, S.; Dikin, D. A.; Stankovich, S.; Piner, R.; Jung, I.; Dommett, G. H. B.; Evmenenko, G.; Wu, S. E.; Chen, S. F.; Liu, C. P.; Nguyen, S. T.; Ruoff, R. S. Graphene-silica composite thin films as transparent conductors. Nano Lett. 2007, 7, 1888-1892.

[19] Wang, X.; Zhi, L. J.; Mullen, K. Transparent, conductive graphene electrodes for dye-sensitized solar cells. Nano Lett. 2008, 8, 323-327.

[20] Blake, P.; Brimicombe, P. D.; Nair, R. R.; Booth, T. J.; Jiang, D.; Schedin, F.; Ponomarenko, L. A.; Morozov, S. V.; Gleeson, H. F.; Hill, E. W.; Geim, A. K.; Novoselov, K. S. Graphene-based liquid crystal device. Nano Lett. 2008, 8, 1704-1708.

[21] Alivisatos, A. P. Semiconductor clusters, nanocrystals, and quantum dots. Science 1996, 271, 933-937.

[22] Fissan, H.; Kennedy, M. K.; Krinke, T. J.; Kruis, F. E. Nanoparticles from the gas phase as building blocks for electrical devices. J. Nanopart. Res. 2003, 5, 299-310.

[23] Novoselov, K. S.; Jiang, D.; Schedin, F.; Booth, T. J.; Khotkevich, V. V.; Morozov, S. V.; Geim, A. K. Twodimensional atomic crystals. P. Natl. Acad. Sci. USA 2005, 102, 10451-10453.

[24] Novoselov, K. S.; Morozov, S. V.; Mohinddin, T. M. G.; Ponomarenko, L. A.; Elias, D. C.; Yang, R.; Barbolina, II; Blake, P.; Booth, T. J.; Jiang, D.; Giesbers, J.; Hill, E. W.; Geim, A. K. Electronic properties of graphene. Phys. Status Solidi B-Basic Solid State Phys. 2007, 244, 4106-4111.

[25] Muszynski, R.; Seger, B.; Kamat, P. V. Decorating graphene sheets with gold nanoparticles. J. Phys. Chem. C 2008, 112, 5263-5266.

[26] Williams, G.; Seger, B.; Kamat, P. V. TiO $\mathrm{Ti}_{2}$-graphene nanocomposites. UV-assisted photocatalytic reduction of graphene oxide. ACS Nano 2008, 2, 1487-1491.

[27] Chen, J. H.; Lu, G. H. Controlled decoration of carbon nanotubes with nanoparticles. Nanotechnology 2006,
17, 2891-2894.

[28] Lu, G. H.; Zhu, L. Y.; Wang, P. X.; Chen, J. H.; Dikin, D. A.; Ruoff, R. S.; Yu, Y.; Ren, Z. F. Electrostatic-force-directed assembly of $\mathrm{Ag}$ nanocrystals onto vertically aligned carbon nanotubes. J. Phys. Chem. C 2007, 111, 1791917922.

[29] Zhu, L. Y.; Lu, G. H.; Chen, J. H. A generic approach to coat carbon nanotubes with nanoparticles for potential energy applications. J. Heat Transf. -Trans. ASME 2008, 130, 044502.

[30] Liu, M.; Lu, G. H.; Chen, J. H. Synthesis, assembly, and characterization of Si nanocrystals and Si nanocrystal carbon nanotube hybrid structures. Nanotechnology 2008, 19, 265705.

[31] Cai, W. W.; Piner, R. D.; Stadermann, F. J.; Park, S.; Shaibat, M. A.; Ishii, Y.; Yang, D. X.; Velamakanni, A.; An, S. J.; Stoller, M.; An, J. H.; Chen, D. M.; Ruoff, R. S. Synthesis and solid-state NMR structural characterization of C-13-labeled graphite oxide. Science 2008, 321, 1815 $-1817$.

[32] Lerf, A.; He, H. Y.; Forster, M.; Klinowski, J. Structure of graphite oxide revisited. J. Phys. Chem. B 1998, 102, 4477-4482.

[33] He, H. Y.; Klinowski, J.; Forster, M.; Lerf, A. A new structural model for graphite oxide. Chem. Phys. Lett. 1998, 287, 53-56.

[34] Stankovich, S.; Piner, R. D.; Chen, X. Q.; Wu, N. Q.; Nguyen, S. T.; Ruoff, R. S. Stable aqueous dispersions of graphitic nanoplatelets via the reduction of exfoliated graphite oxide in the presence of poly(sodium 4-styrenesulfonate). J. Mater. Chem. 2006, 16, 155158.

[35] Park, S.; An, J.; Piner, R. D.; Jung, I.; Yang, D.; Velamakanni, A.; Nguyen, S. T.; Ruoff, R. S. Aqueous suspension and characterization of chemically modified graphene sheets. Chem. Mater. 2008, 20, 6592-6594.

[36] Chen, J. H.; Lu, G. H.; Zhu, L. Y.; Flagan, R. C. A simple and versatile mini-arc plasma source for nanocrystal synthesis. J. Nanopart. Res. 2007, 9, 203-213.

[37] Mao, S.; Lu, G. H.; Chen, J. H. Coating carbon nanotubes with colloidal nanocrystals by combining an electrospray technique with directed assembly using an electrostatic field. Nanotechnology 2008, 19, 455610.

[38] Meyer, J. C.; Geim, A. K.; Katsnelson, M. I.; Novoselov, 
K. S.; Booth, T. J.; Roth, S. The structure of suspended graphene sheets. Nature 2007, 446, 60-63.

[39] Dresselhaus, M. S.; Dresselhaus, G.; Avouris, P. Carbon nanotubes: Synthesis, structure, properties, and applications; Springer: Berlin, New York, 2001.

[40] Morgenstern, K.; Rosenfeld, G.; Comsa, G. Local correlation during Ostwald ripening of two-dimensional islands on $\mathrm{Ag}(111)$. Surf. Sci. 1999, 441, 289-300.

[41] Meyer, R.; Ge, Q. F.; Lockemeyer, J.; Yeates, R.; Lemanski, M.; Reinalda, D.; Neurock, M. An ab initio analysis of adsorption and diffusion of silver atoms on alumina surfaces. Surf. Sci. 2007, 601, 134-145.

[42] Byon, E.; Oates, T. W. H.; Anders, A. Coalescence of nanometer silver islands on oxides grown by filtered cathodic arc deposition. Appl. Phys. Lett. 2003, 82, 1634 -1636 .

[43] Zhu, L. Y.; Lu, G. H.; Mao, S.; Chen, J. H.; Dikin, D. A.; Chen, X. Q.; Ruoff, R. S. Ripening of silver nanoparticles on carbon nanotubes. Nano 2007, 2, 149-156.

[44] Gangopadhyay, P.; Magudapathy, P.; Kesavamoorthy, R.; Panigrahi, B. K.; Nair, K. G. M.; Satyam, P. V. Growth of silver nanoclusters embedded in soda glass matrix. Chem. Phys. Lett. 2004, 388, 416-421.

[45] Heilmann, A.; Werner, J. In situ observation of microstructural changes of embedded silver particles. Thin Solid Films 1998, 317, 21-26.

[46] Wynblatt, P.; Gjostein, N. A. Supported metal crystallites.
Prog. Solid State Chem. 1975, 9, 21-58.

[47] Wynblatt, P.; Gjostein, N. A. Particle growth in model supported metal catalysts-I Theory. Acta Metallurgica 1976, 24, 1165-1174.

[48] Datye, A. K.; Xu, Q.; Kharas, K. C.; McCarty, J. M. Particle size distributions in heterogeneous catalysts: What do they tell us about the sintering mechanism? Catal. Today 2006, 111, 59-67.

[49] Manard, M. J.; Kemper, P. R.; Bowers, M. T. Binding interactions of mono- and diatomic silver cations with small alkenes: Experiment and theory. Int. J. Mass Spectrom. 2005, 241, 109-117.

[50] Yang, D.; Velamakanni, A.; Bozoklu, G.; Park, S.; Stoller, M.; Piner, R. D.; Stankovich, S.; Jung, I.; Field, D. A.; Ventrice Jr., C. A.; Ruoff, R. S. Chemical analysis of graphene oxide films after heat and chemical treatments by X-ray photoelectron and micro-Raman spectroscopy. Carbon 2009, 47, 145-152.

[51] Jung, I.; Dikin, D. A.; Piner, R. D.; Ruoff, R. S. Tunable electrical conductivity of individual graphene oxide sheets reduced at "low" temperatures. Nano Lett. 2008, 8, 4283-4287.

[52] Becerril, H. A.; Mao, J.; Liu, Z.; Stoltenberg, R. M.; Bao, Z.; Chen, Y. Evaluation of solution-processed reduced graphene oxide films as transparent conductors. ACS Nano 2008, 2, 463-470. 